improved analgesia in postoperative abdominal surgery patients even at rest.?

We agree with Drs. Kehlet and Dahl that the addition of local anaesthetics to postoperative epidural opioids is advantageotus, when used in the appropriate concentrations.

N.H. Badner MD FRCPC

London, Ontario

REFERENCES

1 Badner NH. Komar WE. Bupivacaine 0.1\% does not improve postoperative epidural fentanyl analgesia after abdominal or thoracic surgery. Can J Anaesth 1992; 39: $330-6$.

2 Badner NH, Reimer EJ, Komar WE, et al. Low dose bupivacaine does not improve postoperative epidural analgesia in orthopedic patients. Anesth Analg 1991; 72: 337-41.

3 Dahl $J B$, Rosenberg $J$, Hansen $B L$, et al. Differential analgesic effects of low-dose epidural morphine and morphine-bupivacaine at rest and during mobilization after major abdominal surgery. Anesth Analg 1992; 74: 362-5.

4 Logas WG, El-Baz N, El-Ganzouri A. Continuous thoracic cpidural analgesia for postoperative pain relief following thoracotomy: a randomized prospective study. Anesthesiology 1987; 67: 787-9.

5 Cullen ML, Staren ED, El-Ganzouri A, et al. Continuous epidural infusions for analgesia after major abdominal operations: a randomized, prospective, double-blind study. Surgery 1985; $98: 718-28$.

6 Mourisse J, Hasenbas MAWM, Gielen MJM, et al. Epidural bupivacaine, sufentanil or the combination for postthoracotomy pain. Acta Anaesthesiol Scand 1992; 36: $70-4$.

7 Badner NH, Bhandari R, Komar WE, Ganapathy S. $0.125 \%$ bupivacaine - the optimum concentration for postoperative epidural fentanyl; analgesic effects. Can J Anaesth 1992; 39; A71.

\section{Polamedco endotracheal tubes}

To the editor:

I would like to draw the readers' attention to a potential hazard in the use of Polamedco brand endotracheal tubes with Laerdal self-inflating bags. The emergency paramedic service here in Edmonton uses this brand of tube (presumably because of their fitted stylettes) and there have been several incidents of inability to ventilate the lungs with them. By chance, I witnessed one of these.

An intubated and resuscitated cardiac arrest victim was brought into the Emergency Department at one of our hospitals. As I glanced in the room I was urgently summoned by the respiratory technician who was at that moment extubating the trachea and proceeding to ventilate the lungs by mask. He stated that he had, over the course of several minutes, become increasingly unable to ventilate the lungs yet could discover no cause. Later, after discussion with other staff, the mechanism became clear.

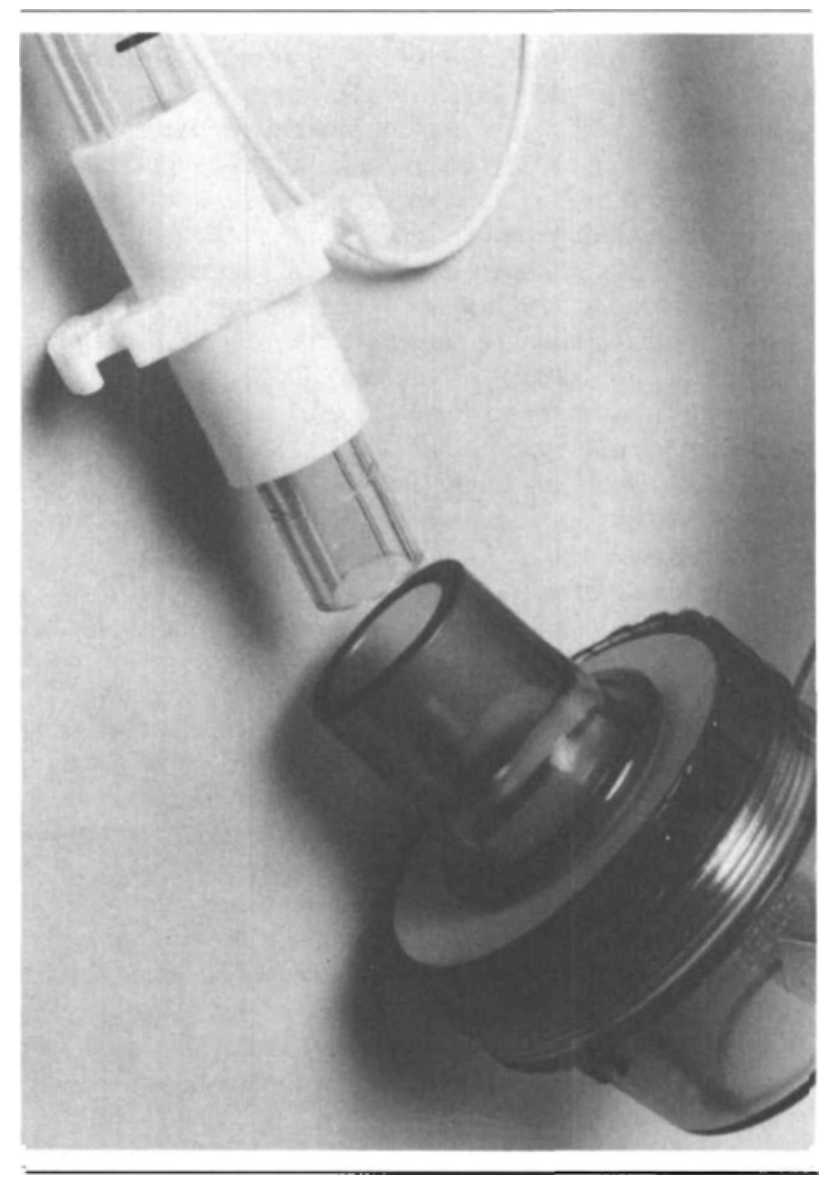

FIGURE Polamedco endotracheal tube and connection to Laerdal inflating bag.

The Polamedco endotracheal tube has an external connector which is fitted over the tube and is held in place by a small flange on the inside of the connector fitting into a crimp around the tube (Figure). With time, downward pressure, and lubrication by secretions, this fitting can slip. The endotracheal tube slides up through the connector and compresses the fish-mouth valve in the Laerdal bag, effectively preventing ventilation. It is extremely difficult to see this even if one knows what to look for.

This problem has arisen several times in our emergency departments and is starting to be appreciated by some of the casualty officers but seems to be relatively unknown amongst anaesthetists. It is important that we recognize this potential hazard early, especially when we receive patients who have been intubated in the lessthan-optimal pre-hospital environment.

\author{
K.R. McCaskill MD \\ University of Alberta Hospitals \\ Edmonton, Alberta
}

